\title{
Optimization of Sperm for In vitro Production of Bovine Embryos
}

\author{
Marko Samardzija ${ }^{1 *}$, Iva Getz ${ }^{1}$, Martina Lojkic ${ }^{1}$, Hrvoje Valpotic ${ }^{1}$, Drazen Djuricic ${ }^{2}$ \\ ${ }^{1}$ Faculty of Veterinary Medicine, Zagreb, Croatia \\ ${ }^{2}$ Veterinary Practice Djurdjevac, Djurdjevac, Croatia
}

Received: June 09, 2015; Accepted: July 13, 2015; Published: September 16, 2015

*Corresponding author: Marko Samardzija, Clinic for obstetrics and reproduction, Faculty of Veterinary Medicine, Heinzelova 55, 10000 Zagreb, Croatia, Tel: +385 12390 321; Fax: + 3851244 1390; E-mail: smarko@vef.hr

\begin{abstract}
The use of in vitro technique with domestic animal gametes and the methods of embryo manipulation of assisted reproduction is currently the most advanced method in cattle breeding with regard to scientific research and practice. The technology of In vitro Production (IVP) of bovine embryos comprises In vitro maturation, In vitro Fertilization (IVF) and In vitro culture until the stage of the blastocyst. During mating, cervical mucus poses a barrier that only allows the migration of spermatozoa with normal morphology, progressive motility, and highly stable nucleus. Fresh ejaculates of bulls usually have more than $80 \%$ of progressively motile spermatozoa and $85 \%$ with morphologically normal shape. Frozen-thawed bull sperm has a lower percentage of progressive motility $(30 \%-70 \%)$ so special attention should be paid during optimization to the methods of sperm preparation for assisted reproduction such as IVP. With the use of such procedures, the sperm quality could be significantly improved by enhancing progressive motility and increasing the number of morphologically normal spermatozoa. Such selection of spermatozoa separates motile sperm from non-motile, removes seminal plasma, cryoprotective agents, other background materials and debris, and also at the same time initiates sperm capacitation. The efficacy of sperm preparation methods could be evaluated by using different sperm parameters such as: sperm motility, morphology, concentration, viability, membrane activity, acrosome status, reactive oxygen species formation, chromatin maturity and integrity, protamination degree and IVP rates. The aim of the current review is to consider and discuss scientific data regarding the necessity of bull sperm optimization for an IVF procedure in order to improve IVP efficiency of bovine embryos. It could be concluded that the use of different sperm optimization methods for IVF is essential in order to improve the quality of obtained sperm. However, it would be advisable to extend the comparison of sperm preparation methods by transfer of IVP embryos into recipient cows which will allow more reliable results of subsequent embryo development.
\end{abstract} Bull

Keywords: In vitro production; Optimization methods; Sperm

\section{Introduction}

The use of in vitro technique with domestic animal gametes and the methods of embryo manipulation for assisted reproduction is currently the most advanced method in cattle breeding with regard to scientific research and practice. The technology of In vitro Production (IVP) of bovine embryos comprises In vitro Maturation (IVM), In vitro Fertilization (IVF) and In vitro Culture (IVC) until the stage of blastocyst [1]. The IVP enables the production of numerous offspring from genetically highquality cows and thus it is in use in order to attain improvement of genetic selection in cattle breeding, as an alternative to the classical embryo transfer technique. The efficiency of IVP in a commercial system is measured by the number of pregnant cows following transfer so the selection of "good quality" embryos is a crucial step in influencing the outcome of this technology [2]. During mating, cervical mucus poses a barrier that only allows the migration of spermatozoa with normal morphology, progressive motility, and highly stable nucleus. Fresh ejaculates of bulls usually have more than $80 \%$ of progressively motile spermatozoa and $85 \%$ with morphologically normal shape. Frozen-thawed bull sperm has a lower percentage of progressive motility (30\%-70\%) [3]. The Aim of the cattle breeding industry is to identify genetically superior bulls and maximize the number of offsprings produced by selected bulls via Artificial Insemination (AI). The fertility of these bulls is important in achieving this aim. In the past, the laboratory evaluation of bull semen was based entirely on the subjective scoring of sperm motility under a light microscope and the measurement of sperm concentration. Occasionally, morphology was determined when certain pathologies were suspected. Use of these assessment procedures and a single protocol of freezing have led to the formation of very homogeneous sire populations in this respect. The sires still exhibit varying results with regard to field fertility. According to current knowledge, the assessment of ejaculate as a whole is erroneous [4]. It is necessary to separate the most viable spermatozoa from the bulk [5]. Hence, during optimization of frozen-thawed bull sperm for IVF special attention should be paid to the methods for selection of progressively motile spermatozoa [3]. With the use of such procedures, the sperm quality could be significantly improved by enhancing progressive motility and increasing the number of morphologically normal spermatozoa. Spermatozoa and leukocytes produce many oxygen radicals that alter the possibility of the sperm-oocyte fusion after repeated centrifugations, so the selection of sperm from other components with such procedures must be preferred [6]. This is the main 
reason why sperm separation methods have a very important role in the IVP. Such selection of spermatozoa separates motile sperm from non-motile, removes seminal plasma, cryoprotective agents, other background materials and debris, and also at the same time initiates sperm capacitation [7]. The aim of the current review is to consider and discuss scientific data regarding the necessity of bull sperm optimization for an IVF procedure in order to improve IVP efficiency of bovine embryos.

\section{Capacitation and Acrosome Reaction (AR)}

Some physiological processes during fertilization (capacitation, AR, the fusion of sperm and ovum) essentially need an active membrane, because it is impossible to have fertilization with a physically inactive membrane. Capacitation is a sequence of biochemical changes leading to destabilization of sperm membrane which enables the sperm to become able for fertilization [8]. Capacitation involves sperm plasma membrane events that lead to an increased cellular calcium influx, fusion and vesiculation of the plasma and outer acrosome membranes, and the loss of the acrosome protein matrix in a process termed AR. Normal AR of spermatozoa is an essential requirement for mammalian fertilization. The importance of capacitation is evident at 3 levels: hypermotility of sperm (1) enabling spermatozoa to penetrate cumulus oophorus (2) and preparation of sperm for AR (3). During AR, hydrolytic enzymes and proteases are released, including hyaluronidase enabling sperm to penetrate through the extracellular matrix of cumulus oophorus and zona pellucida surrounding oocytes. This reaction occurs only in live spermatozoa and is termed the real AR following which spermatozoa lose their acrosome. In contrast, the false AR could happen in dead spermatozoa as post-mortal change characterized by serious damage of acrosome and plasma membrane [9].

\section{IVP of Bovine Embryos}

The IVP comprising IVM, IVF and IVC of fertilized oocytes during 7 days till the stages of morula or blastocyst [2]. The oocytes for in vitro production of bovine embryos could be collected from ovaries the following slaughter as well as from live donor cows by the method of transvaginal aspiration of follicles also termed Ovum pick-up (OPU). Slaughterhouse derived ovaries contain a highly heterogeneous population of oocytes that are recovered regardless of follicular dynamics and may be obtained from cattle with diverse reproductive backgrounds. Production of embryos from slaughterhouse ovaries begins with oocytes collected from all follicles visible on the surface of the bovine ovary. Oocytes obtained from slaughtered animals are variable in their developmental competence after IVM [10]. One of the main disadvantages of this technology is the lack of reproducibility. Once the cow has been slaughtered, no further collection of oocytes from the same donor is possible. Oocytes are more frequently recovered from live animals by transvaginal ultrasound-guided oocyte collection or OPU. In conjunction with IVP, this technique provides an alternative mean to increase the number of offspring from genetically valuable cows [11]. Differences between the slaughterhouse and OPU-derived oocytes have previously been reported with controversial results [11-14].

\section{In vitro Maturation (IVM)}

In the procedure of IVM, the oocytes are collected from follicles visible at the surface of ovarium with a diameter over $3 \mathrm{~mm}$, surrounded by a multilayer of cumulus cells and with homogeneous ooplasm [14]. During maturation of bovine oocytes, there is an ongoing proliferation of cumulus cells, continuation of meiosis, and reorganization of their cytoplasmic organelles. The success of IVM of bovine oocytes is measured by morphological assessment of proliferation of cumulus oophorus and corona radiata cells. The degree of nucleus maturation is measured as a percentage of oocytes in the stage of metaphases II (MII) with the first polar body expelled [2]. According to Lonergan, et al. [15], the success of IVM of bovine oocytes is approximately $90 \%$, but only $30 \%$ of oocytes develop to the stadium of the blastocyst.

\section{In vitro Fertilization (IVF)}

The IVF is a mixed cultivation of mature oocytes with spermatozoa in strictly controlled laboratory conditions. The co-incubation of spermatozoa with oocytes lasts for 24 hours, at $39^{\circ} \mathrm{C}$ with $5 \% \mathrm{CO}_{2}$ in the air and $80 \%$ humidity after which the first mitosis occurs [2]. The success of IVF of bovine oocytes is estimated 48 hours following fertilization by a number of cleaved embryos and by identification of male and female pronucleus which may be visible after 18-22 hours of co-incubation [16].

\section{In vitro Culture (IVC)}

The fertilized oocytes are cultured in vitro to the blastocyst stage when such embryos may be transferred into a recipient or frozen and stored in liquid nitrogen. The IVC lasts for 7 days in desirable defined sequential media to satisfy energetic needs of the pre-implantation embryo [3]. During IVC, the embryo is passing through 4 important developmental stages: the first mitosis, activation of embryonic genome, compaction in morula stage, the formation of the blastocyst with differentiation of their cells. Unfavorable conditions during IVC may affect any of the mentioned stages and negatively influence the quality of cultivated blastocyst. The quality of the embryo has further influenced the success of freezing as well as the percentage of conception after transferring to the recipient animal. Although, numerous methods are used to evaluate embryo quality, the assessment of this quality presents a challenge for embryologist in selecting the best quality embryos to transfer to the recipient. The simplest and most widespread method to determine the embryo quality is a morphological evaluation, which is at the same time, the most subjective method [2].

\section{Sperm Optimization for IVP}

Mammalian spermatozoa have very expressive heterogeneous traits in morphology, motility and nuclear stability. Following mating, spermatozoa are located in the female genital tract. However, in natural conditions their metabolism is not adapted to survive for long periods of time in In vitro conditions [9]. During transport in the female genital tract and following sperm- 
oocyte interaction, only spermatozoa with certain quality are selected. It could be hypothesized that evaluating the population of inseminate, which In vivo would potentially reach the ovum, would give a more realistic picture about its fertilizing ability [17]. During the optimization of frozen-thawed bull sperm for IVF special attention should be given to the methods of selection of progressively motile sperm. Sperm separation procedures are able to significantly improve the sperm quality with a higher rate of progressive motility and morphologically normal spermatozoa. For this reason, sperm separation methods have a very important role in an IVP. Such selection of spermatozoa separates motile sperm from non-motile, removes seminal plasma, cryoprotective and infectious agents, other background materials and debris and also at the same time initiates sperm capacitation [7]. The morphological selection of spermatozoa in the prepared population varies, mostly with the tail and midpiece defects being primarily excluded [17]. Therefore, there is a need for a simple and quick sperm selection procedure that would yield sufficient numbers of purified high-quality spermatozoa [18]. Some of the most important methods for separation of spermatozoa from seminal plasma are: bovine serum albumin (BSA), washing [17], selective fractionation of sperm by centrifugation in density gradient (DGC), such as Percoll ${ }^{\circledR}[19,20,21,22]$ and BoviPure ${ }^{\circledR}$ $[14,20,21,23]$, selective filters: Sephadex [24], glass wool [9] for the migration of spermatozoa by classical swim up (SU) technique $[21,25]$ as well as SU with the addition of hyaluronic acid $[3,16]$ and others.

Up to now there have been many studies regarding the efficiency of numerous sperm optimization methods in bovine IVF procedures. The DGC has been used to improve subsequent IVF outcome [26]. It has also been used for the retrieval of best spermatozoa from sub-standard bull ejaculates [17] or for spermatozoa subjected to freezing-thawing [27] and highspeed sorting procedures [28]. These procedures have not been extensively used by animal breeders due to lack of special formulations for domestic animals [29]. Until recently, Percoll ${ }^{\circledR}$ gradient was the most widely used methods in the preparation of bull sperm for IVF [30]. Getz, [31] compared the SU method vs. Percoll ${ }^{\circledR}$ for the bovine IVF of ova and found that the Percoll ${ }^{\circledR}$ method is simple, fast and resulted in a higher percentage of progressively motile sperm cells (65\%) vs. the SU method (50\%). Percoll $^{\circledR}$ (Pharmacia, Uppsala, Sweden) is a density gradient medium which is used for the purification of cells, viruses and organelles [19]. The separation of highly motile spermatozoa for IVF is performed by centrifugation in discontinues gradient of Percoll ${ }^{\circledR}$, which forms density gradients during centrifugation due to the great difference in particle size of medium and fractional purified spermatozoa from debris such as bigger particles of Polyvinylpyrrolidone (PVP), different cells and bacteria. Repeated centrifugation/ resuspension are a simple procedure which results in a final pellet with a large number of live spermatozoa [18]. The use of Percoll ${ }^{\circledR}$ can lead to a highly purified semen sample. However, PVP-coated silica particles used in Percoll ${ }^{\circledR}$ are restricted to non-clinical use due to their toxic effects on sperm [4,19] and embryo development [30]. Samardzija, et al. [22] established highly significant differences $(P<0.01)$ between initial parameters of bull sperm and their parameters after sperm optimization by using Percoll ${ }^{\circledR}$ which is in agreement with the results reported by Tanghe, et al. [32]. In addition, Samardzija, et al. [22] reported a highly significant, positive correlation between results of IVF $(r>0.5 ; P<0.05)$. However, they did not find the same results between sperm parameters and results of IVF $(r<0.5 ; P<0.05)$. As a result of Percoll ${ }^{\circledR}$ endotoxicity many pharmaceutical companies have been searching for a quality alternative to Percoll ${ }^{\circledR}$ such as Bovipure ${ }^{\circledR}$ (Nidacon, International AB, Mölndal, Sweden). Non-toxic alternatives have been created for some species (PureSperm ${ }^{\circledR}$ for humans, Bovipure ${ }^{\circledR}$ for bulls, EquiPure ${ }^{\circledR}$ for stallions and PorciPure ${ }^{\circledR}$ for boars semen) but the recovery rates and selection abilities have been variable $[20,21,23]$. BoviPure ${ }^{\circledR}$ is a commercial medium for DGC. It is an iso-osmotic salt solution containing colloidal silica particles coated with silane formulated specifically for bull sperm use. At the moment, very few studies have been conducted to evaluate BoviPure $^{\circledR}$ for IVP of bovine embryos $[14,20,21,23]$. Comparing the initial sperm results of HOS, SYBR-14/PI and EthD-1/FITCPSA tests with results of these tests after Percoll ${ }^{\circledR}$ and Bovipure ${ }^{\circledR}$ sperm separation protocols, the authors reported significantly better results with Bovipure ${ }^{\circledR}(P<0.001)$. These results indicate that both protocols, Percoll ${ }^{\circledR}$ and BoviPure ${ }^{\circledR}$, improve the quality of separated sperm in regard to higher viability and acrosome integrity. Samardzija, et al. [20] also compared the results of IVF and IVC of both sperm separation protocols and found a high, significant correlation between the sperm parameters and IVF results $(r<0.5 ; P<0.05)$. The cleavage (D2) and blastocysts (D7) rate were significantly higher $(P<0.05)$ for the BoviPure ${ }^{\circledR}$ group compared to the Percoll ${ }^{\circledR}$ group. However, the number of hatched blastocysts (D10) did not differ significantly between the sperm separation protocols. Sieren and Youngs [23] reported that bull sperm preparation by BoviPure ${ }^{\circledR}$ did not show significantly better effects on the percentage of ova cleavage 48 hours after the insemination $(77.20 \%)$ and on the percentage of formed blastocysts after 8 days of IVC $(21.60 \%)$ in comparison with the SU (71.90 and $17.10 \%$, respectively). This result demonstrated that the preparation of bull sperm by BoviPure ${ }^{\circledR}$ did not significantly improve the ability of producing the bovine embryos in IVP, which is not congruent with the results of Samardzija, et al. [20]. Although sperm evaluation parameters did not differ between these two protocols, superior cleavage rates and embryo production following BoviPure ${ }^{\circledR}$ compared to Percoll ${ }^{\circledR}$ separation was not recorded. In addition, these results suggest that BoviPure ${ }^{\circledR}$ is a good and acceptable alternative to Percoll ${ }^{\circledR}$ for bull sperm separation for the IVF.

Recently, new colloid formulations containing glycidoxypropyltrimethoxysilane - coated silica have been designed especially for the domestic animal species (Androcoll) and tested In vitro in a modified procedure, centrifugation on a Single Layer Of Colloid (SLC), which allows easy separation of high volumes (whole ejaculate) of spermatozoa with improved quality (motility, morphology, chromatin stability). Thus, time is saved during preparation and the method can be scaled-up successfully to allow large volumes of ejaculate to be centrifuged $[33,34]$. 
The only study on bull semen [33] was testing the IVF of previously centrifuged (SLC) frozen-thawed semen. From the studies mentioned above, it could be concluded that after SLC, spermatozoa exhibit increased proportion of morphologically normal spermatozoa, increased overall and progressive motility, increased velocity of movement and higher proportion of sperm cells with intact chromatin.

Also, the proportion of cells with high mitochondrial membrane potential increases and IVF results do not differ from those obtained with centrifugation in Percoll $^{\circledR}$. When spermatozoa are centrifuged through a single layer of silane coated silica particles, they cleanse from seminal plasma (in case of fresh semen), which has been proved to be useful for chromatin stability of spermatozoa, particularly if dilution and freezing follows [35].

Beside the mentioned methods, the SU has been in routine use for many years in the optimization of sperm in IVP of bovine embryos $[21,36]$. The SU is the most common technique used in IVF laboratories and is preferred if the semen sample has a normal number of good sperms (normozoospermia). By this technique,the spermatozoa are selected based on their motility and the capability to swim out of the seminal plasma [37]. The SU technique is based on the ability of sperm to spontaneously migrate in the medium in which they are in contact. Due to this phenomenon several modification of SU for separation of the most motile fraction of spermatozoa from ejaculate have been described. The hyaluronic acid is one of the most prevalent glycosaminoglycan in uterine secretions, oviducts and follicular fluid in sow, cow and woman. After their addition in the SU medium, it facilitates separation and selection of high-quality spermatozoa [3].With this procedure, it is possible to reliably separate spermatozoa based on their motility and morphology [17]. The use of spermatozoa migrating ability in SU procedure provides samples with highly motile spermatozoa but yields only around $10-20 \%$ for clean semen or below $10 \%$ of the original sample when frozen-thawed semen is used $[17,18]$. By comparison of different sperm preparation methods, the SU provided spermatozoa with significantly higher motility, average path velocity, membrane integrity and chromatin stability compared to either tha?wed sample or washing treatment $[18,38]$. The SU also revealed changes between different ages of the sires and seemed helpful in distinguishing relationships between sperm quality and fertility among bulls in a homogeneous sire population. However, as SU requires spermatozoa incubation time of about 1hour and also special skills by the operator, an easier and less time-consuming test would meet AI centers needs in a better way. In addition, SU could only be used in AI center for monitoring fresh semen quality but not for the improvement of the whole ejaculate quality prior freezing $[39,40]$.

Comparing SU, and Percoll ${ }^{\circledR}$ gradient Parrish, et al. [41] obtained similar sperm results in both methods, although a lower concentration was recorded in SU. However, the fact that cleavage rate was significantly higher in SU compared to Percoll ${ }^{\circledR}$ compensated a lower sperm concentration results. With SU we can safely separate spermatozoa based on their motility and morphology [17]. The SU method and the DGC produce different levels of contamination in the sample in the final preparation. In fact, the SU technique produces a higher level of non-sperm components (e.g. debris, bacteria) and the diffusion of other substances (e.g. the prostatic zinc) from the semen into the overlaying medium respect of the DGC [42]. Some differences also exist in the presence and production of the ROS and the damage of sperm DNA, associated with high ROS levels, after application of the two main techniques [43]. The SU technique produces a higher level of non-sperm components respect of the DGC. The DGC recovers spermatozoa with improved motility but lower DNA integrity instead of the SU technique, as suggested by Zini, et al.[44]. several studies demonstrate that sperm DNA damage is associated with lower natural pregnancy rates [45] and lower intrauterine insemination pregnancy rates [46].

In addition, Samardzija, et al. [21] compared Bovipure ${ }^{\circledR}$ and SU and reported that BoviPure ${ }^{\circledR}$ is an acceptable method for sperm separation in bovine IVP which is in accordance to the results by Karadjole, et al. [14]. Samardzija, et al. [21] found significantly higher blastocyst rates in BoviPure ${ }^{\circledR}$ group vs. SU group which allowed them to suggest that BoviPure ${ }^{\circledR}$ method made faster cleavage and blastocyst yield possible compared to the SU. Other possible explanation of different embryo yield could be attributed to the DGC methods ability to select spermatozoa with more compacted chromatin and less nuclear DNA damage compared to SU [29]. Embryos from BoviPure ${ }^{\circledR}$ treated the group displayed significantly higher total cell number compared to SU group. Cesari, et al. [47] compared two bull sperm separation methods and revealed a significantly higher number of Inner Cell Mass (ICM) cells in Percoll ${ }^{\circledR}$ treated group as compared to SU. Samardzija, et al. [21] also demonstrated that BoviPure ${ }^{\circledR}$ method resulted in a significantly higher number of ICM cells compared to SU which can be correlated with embryo quality. Although differences were found in cell counts, sperm treatment did not affect hatching rates. These results showed a predominance of sperm preparation by BoviPure ${ }^{\circledR}$ in terms of blastocyst formation, total cell number and allocation of ICM. Lane and Gardner [48] reported that mouse fetal development after the transfer was positively correlated with the number of blastocyst cells and with ICM development, but not with the number of trophectoderm cells or hatching ability. Therefore, it would be advisable to extend the comparisons of these two sperm preparation methods by transfer of IVP embryos into recipient cows which will allow more reliable results of subsequent embryo development.

\section{Semen Evaluation Parameters}

The efficacy of sperm preparation methods could be evaluated using different sperm parameters such as sperm motility, morphology, concentration, viability, membrane activity, acrosome status, ROS formation, chromatin maturity and integrity, protamination degree and IVP rates $[20,49]$. Standard semen analysis methods offer basic information on spermatogenesis, long life and sperm fertility [50]. These methods are primarily based on physical parameters such as progressive motility, sperm morphology and sperm concentration in the semen. In any case, these standard parameters as used in 
the evaluation of fertility in males have a limited capacity in predicting their fertilizing potential [9]. Until recently evaluation of sperm motility was considered as a reliable sperm quality indicator. Most authors usually agree that there is a positive correlation between sperm motility and fertility, and also agree that it is relatively low [51]. Correlation between sperm fertility and motility is pretty controversial, most likely due to different test conditions [52]. One of the most important aims in spermiology is the testing of new methods in sperm evaluation to discover their characteristic changes, which would point out infertility or subfertility in sires. The functional and structural integrity of sperm membrane is crucial for the viability of spermatozoa [53]. The best evaluation of fertility can be achieved with a combination of results from the evaluation of plasma membrane integrity and motility [9]. Due to the great importance of sperm membrane in fertilization, considerable attention is given to membrane integrity in spermiogram evaluation. To evaluate plasma membrane integrity two simple basic tests are used: supravital staining (eosin/nigrosin) and hypo-osmotic swelling (HOS) assay [51]. Some physiological processes during fertilization (capacitation, AR, fusion of sperm and ovum) are associated with an active membrane, and it is impossible to have fertilization with a physically inactive membrane. The HOS test was used to evaluate the functional integrity of ram stallion, buck, dog, bull and boar sperm membrane $[20,51,54,55]$. In a hypo-osmolar solution, fluid is transferred into the cell through the plasma membrane of spermatozoa. In an attempt to achieve a balance between intracellular and extracellular spaces, a functionally intact membrane begins to swell starting at the tail of the spermatozoa. The swelling of the membrane leads to curling and invagination. The changes in tail fibers are clearly visible under a phase-contrast microscope. Such spermatozoa are denoted as swollen or HOS reactive (HOS+), signifying functionally intact membranes. Spermatozoa with a functionally defective membrane do not swell and their tails do not invaginate. The osmolarity of the solution should be sufficient to provoke the best effect without lysing the sperm membrane [51]. Fertilization of oocyte will not occur if the sperm membrane is biochemically inactive, even if it remains structurally intact. The HOS test is, therefore, a better indicator of fertilization potential than supravital staining [56]. Supravital staining is based on the fact that the membrane of dead spermatozoa permits the passage of the red stain into the cytoplasm, but the membranes of live spermatozoa do not permit that. This means that all dead spermatozoa in ejaculate will be colored, while live spermatozoa will remain colorless. In the last 15 years, the SYBR14 / Propidium Iodide (PI) test was often used in the evaluation of bull sperm membrane. The integrity of plasma membrane reflects the viability of spermatozoa and can be assessed by dual staining of the membrane with permanent nucleic acid stain, SYBR-14, combined with PI. The fluorescent stain SYBR-14 in combination with PI represents double fluorescence staining. It is used in the evaluation sperm cell membrane integrity and it is one of the most frequently used fluorescent markers in determining the proportion of live spermatozoa in ejaculate sample. The SYBR14 enters through nucleus membrane and stains DNA in green, exclusively in live spermatozoa with an intact cell membrane. The PI is also a fluorescent stain which stains the nucleus of spermatozoa (DNA) with the damaged membrane in red. Such stained spermatozoa can be detected by flow cytometry or by fluorescence microscopy. The normal AR of spermatozoa is an essential requirement for mammalian fertilization [9]. In addition, fluorescein-conjugated plant lectins have been shown to be useful in selective acrosome staining of a stallion, ram, bovine and human spermatozoa $[20,21]$. Their advantage is that they can be labeled by fluorescence markers such as fluorescein isothiocyanate (FITC), and are very stable so the labeling can be performed very quickly. The main disadvantages of this method is that spermatozoa generally need to be fixed in some degree and if the target for staining is within a cell it is necessary that cell membrane be permeabilized by using of different detergents or solutions [9].

\section{Conclusion}

It is essential to select the most motile and normal morphological spermatozoa from the ejaculate as soon as possible, first because some components of the ejaculate contrast with the fertilizing capability of the spermatozoa [42]. Then, because spermatozoa and leukocytes produce many oxygen radicals that can negatively influence the fertilizing sperm function [43,57]. Hence, the methods that separate the functional spermatozoa from the other cells must be preferred. The choice of the best method to select the functionally competent spermatozoa depends on the features of the samples. The SU technique and the DGC have different efficiency in separating the spermatozoa: the spermatozoa isolated with the SU are clean and motile but, damaged by the ROS and with higher DNA integrity while the spermatozoa isolated with the DGC are not damaged by the ROS but with low DNA integrity [58]. Any selection mechanisms taking place in vitro must not harm the spermatozoa or modulate their interaction with the female reproductive tract if fertility is to be maintained [25].

It can be concluded that the use of different methods of sperm optimization in IVF is essential regarding the improvement of separated sperm quality. However, since methods of sperm optimization by using DGC are based on 2 layers, recent investigations are directed towards simplification of these techniques in order that one layer will be applied. Since such technique is simple, quick and seems to consistently select highquality sperm, it could be of considerable benefit in bovine IVF laboratories. Since the data regarding centrifugation on a single layer of colloid is still insufficient, especially for bulls, there is a need to examine the above mentioned method for its suitability to maintain/improve bull semen quality before freezing and also its suitability as a preparatory sperm selection method for IVP [34]. In addition, it would be advisable to extend the comparisons of sperm preparation methods by transfer of IVP embryos into recipient cows which will allow more reliable results of subsequent embryo development.

\section{References}

1. Tomašković A, Makek Z, Dobranic T, Samardzija M. Reproduction of 
cows and heifers. (M. Samardzija, S. Vince and J. Grizelj, eds.). Faculty of Veterinary Medicine, University of Zagreb, Croatia. 2007 (In Croatian).

2. Lojkić M, Čavlek M, Bačić G, Getz I, Samardžija M, Maćešić N, et al Morphology evaluation of bovine embryos produced in vitro. Vet. stn 2014;45(3):187-193.

3. Samardžija M, Karadjole M, Cergolj M, Tomašković A, Dobranić T, Getz I, et al. The comparison of the two bull sperm separation methods for in vitro fertilization. Tierarztl. Umschau. 2005;60(4):193-199.

4. Mortimer D. Sperm preparation methods. J Androl. 2000;21(3):357366.

5. Marcias Garcia B, Morrell JM, Ortega-Ferrusola C, Gonzalez-Fernandez L, Tapia JA, Rodriguez-Martinez $\mathrm{H}$, et al. Centrifugation on a single layer of colloid selects improved quality spermatozoa from frozenthawed stallion semen. Anim Reprod Sci. 2009;114:193-202. doi: 10.1016/j.anireprosci.2008.08.025.

6. Aitken, RJ, Clarkson JS. Significance of Reactive Oxygen Species and Antioxidants in Defining the Efficacy of Sperm Preparation Techniques. J Androl. 1988;9(6):367-376.

7. Centola GM, Herko R, Andolina E, Weisensel S. Comparison of sperm separation methods: effect on recovery, motility, motion parameters, and hyperactivation. Fertil Steril. 1998;70:1173-1175.

8. Van Soom A, de Kruif A. Oocyte maturation, sperm capacitation and pre-implantation development in the bovine: implications for in vitro production of embryos. Reprod Dom Anim. 1996;31:687-701.

9. Cergolj M, Samardzija M. Veterinary andrology. (M. Samardzija, ed.) Faculty of Veterinary Medicine, University of Zagreb, Croatia. 2006 (In Croatian).

10. Bilodeau-Goeseels S, Panich P. Effects of oocyte quality on development and transcriptional activity in early bovine embryos. Anim Reprod Sci. 2002;71:143-155.

11. Getz I, Karadjole M, Matković M, Karadjole T, Bačić G, Makek Z, et al Comparison of different synchronization treatments in donor heifers for embryo production in vitro. Vet. arhiv. 2011; 81:554-556.

12. Lopes AS, Martinussen T, Greve T, Callesen H. Effects on days postpartum breed and Ovum pick-up scheme on bovine oocyte recovery and embryo development. Reprod Dom Anim. 2006;41:196-203.

13. Merton JS, Otter T, Aerts B, Mullaart E. Effect of oocyte collection method and breed on efficiency of oocyte collection and subsequent in vitro bovine embryo production. Proceedings of the 24thAnual Meeting European Embryo Transfer Association, 12-13 September, Pau, France, 2008; p. 208.

14. Karadjole M, Getz I, Samardžija M, Maćešić N, Matković M, Makek $\mathrm{Z}$, et al. Developmental competence of bovine immature oocytes and quality of embryos derived from slaughterhouse ovaries or live donors by ovum pick up. Vet. arhiv. 2010;80:445-454.

15. Lonergan P, Rizos D, Fair T, Boland MP. In vitro production of bovine embryos: factors affecting blastocyst yield and quality. Proceedings of the $4^{\text {th }}$ Middle-European Buiatric Congress, 23-27 April. Lovran, Croatia. 2003; Pp. 33-38.

16. Leibfried-Rutledge ML, Critser ES, Parrish JJ, First NL. In vitro maturation and fertilization of bovine oocytes. Theriogenology. 1996;31(1):61-74.

17. Rodriguez-Martinez H, Larsson B, Petroft H. Evaluation of sperm damage and techniques for sperm clean-up. Reprod Fertil Develop. 1997;9(3):297-308.
18. Hallap T, Haard M, Jaakma Ü, Larsson B, Rodriguez-Martinez H. Does cleansing of frozen-thawed bull semen before assessment provide samples that relate better to potential fertility? Theriogenology. 2004;62(3-4):702-713.

19. Avery B, Greve T. Impact of Percoll on bovine spermatozoa used for in vitro insemination. Theriogenology. 1995; 44(6):871-878.

20.Samardzija M, Karadjole M, Matkovic M, Cergolj M, Getz I, Dobranic T, et al. A comparison of BoviPure and Percoll on bull sperm separation protocols for IVF. Anim Reprod Sci. 2006;91(3-4):237-247.

21.Samardzija M, Karadjole M, Getz I, Makek Z, Cergolj M, Dobranic T. Effects of bovine spermatozoa preparation on embryonic development in vitro. Reprod Biol Endocrinol. 2006;4:58.

22. Samardžija M., Dobranić T, Karadjole M, Getz I, Vince S, Gračner D, et al. The efficacy of gradient Percoll on bull sperm separation for in vitro fertilization. Vet. arhiv. 2006c;76:37-44.

23. Sieren KR, Youngs CR. Evaluation of Bovipure ${ }^{\mathrm{TM}}$ for in vitro production of bovine embryos. Theriogenology. 2001; 55:438.

24. Correa JR, Zavos PM. Preparation and recovery of frozen-thawed bovine spermatozoa via various sperm selection techniques employed in assisted reproductive technologies. Theriogenology. 1996;46(7):1225-1232.

25. Morell JM, Rodriguez-Martinez H. Practical Applications of Sperm Selection Techniques as a Tool for Improving Reproductive EfficiencY. Vet Med Int. 2010;2011:894767. doi: 10.4061/2011/894767.

26. Tomlinson MJ, Moffat O, Manicardi GC, Bizzaro D, Afnan D, Sakkas D. Interrelationships between seminal parameters and sperm nuclear damage before and after density gradient centrifugation; implications for assisted conception. Human Reprod. 2001;16(10):2160-2165.

27. Maxwell WMC, Parrilla I, Caballero I, Garcia E, Roca J, Martinez EA, Vasquez JM, et al. Retained functional integrity of bull spermatozoa after double freezing and thawing using PureSperm density gradient centrifugation. Reprod Dom Anim. 2007;42(5):489-494.

28. Hollinshead FK, O`Brien JK, Maxwell WMC, Evans G. Assessment of in vitro sperm characteristics after flow cytometric sorting of frozenthawed bull spermatozoa. Theriogenology. 2004;62(5):958-968.

29. Morrell JM. Update on semen technologies for animal breeding. Reprod Dom Anim. 2006;41:63-67.

30. Mendes JOB, Burns PD, De La Torre-Sanchez JF, Seidel GE. Effect of heparin on cleavage rates and embryo production with four bovine sperm preparation protocols. Theriogenology. 2003;60(2):331-340.

31. Getz I. In vitro maturation, fertilization and culture of bovine oocytes. Master Thesis. Zagreb, 1999.

32. Tanghe S, Van Soom A, Sterckx V, Maes D, de Kruif A. Assesment of different sperm quality parameters to predict in vitro fertility of bulls. Reprod Dom Anim. 2002;37(3):127-132.

33. Thys M, Vandaele L, Morrell JM, Mestach J, Van Soom A, Hoogewijs M, et al. In vitro fertilizing capacity of frozen-thawed bull spermatozoa selected by single layer (glycidoxypropyltrimethoxysilane) silane-coated silica colloidal centrifugation. Reprod. Dom. Anim. 2009;44:390-394. doi: 10.1111/j.1439-0531.2008.01081.x.

34. Morrell JM, Johannisson A, Dalin A-M, Rodriguez-Martinez H. Morphology and chromatin integrity of stallion spermatozoa prepared by density gradient and single layer centrifugation through silica colloids. Reprod Dom Anim. 2009;44:512-517. doi: 10.1111/j.14390531.2008.01265.x 
35. Love CC. The sperm chromatin structure assay: a review of clinical applications. Anim Reprod Sci. 2005;89(1-4):25-39.

36. Allamaneni SSR, Agarwal A, Rama S, Ranganathan P, Sharma RK Comparative study on density gradients and Swim-up preparation techniques utilizing neat and cryopreserved spermatozoa. Asian J Androl. 2005;7:86-92.

37. Henkel RR, Schill W-B. Sperm preparation for ART. Reprod Biol Endocrinol. 2003;1:108.

38. Hallap T, Nagy Sz, Håård M, Jaakma Ü, Johannisson A, RodriguezMartinez H. Sperm chromatin stability in frozen-thawed semen is maintained over age in AI bulls. Theriogenology. 2005; 63(6):17521763.

39. Hallap T, Haard M, Jaakma Ü, Larsson B, Rodriguez-Martinez H Variations in quality of frozen-thawed semen from Swedish Red and White AI sires at 1 and 4 years of age. Intern J Androl. 2004;27(3):166171.

40. Hallap T, Jaakma Ü, Rodriguez-Martinez H. Changes in semen quality in Estonian Holstein AI bulls at 3, 5 and 7 years. Reprod Dom Anim. 2006;41:214-218.

41.Parrish JJ, Krogenaes A, Susko-Parrish JL. Effect of bovine sperm separation by either swim up or Percoll method on success of in vitro fertilization and early embryonic development. Theriogenology. 1995;44(6):859-869.

42. Bjorndahl L, Mohammadieh M, Pourian M, Soderlund I, Kvist U. Contamination by seminal plasma factors during sperm selection. J Androl. 2005;26(2):170-173.

43.Zini A, Sigman M. Are tests of sperm DNA damage clinically useful? Pros and cons. J Androl. 2009;30:219-229.

44.Zini A, Finelli A, Phang D, Jarvi K. Influence of semen processing technique on human sperm integrity. Urology. 2000; 56(6):10811084.

45. Loft S, Kold-Jensen T, Hjollund NH, Giwercman A, Guyllemborg, Ernest $\mathrm{E}$, et al. Oxidative DNA damage in human sperm influences time to pregnancy. Hum Reprod. 2003;18:1265-1272.

46. Evenson DP, Wixon R. Data analysis of two in vivo fertility studies using Sperm Chromatine Structure Assay-derived DNA fragmentation index vs. Pregnancy outcome. Fertil Steril. 2008;90(4):1229-1231. doi: 10.1016/j.fertnstert.2007.10.066.

47. Cesari A, Kaiser GG, Mucci N, Mutto A, Vincenti A, Fornes MW, et al Integrated morphophysiological assessment of two methods for sperm selection in bovine embryo production in vitro. Theriogenology.

\section{6;66(5):1185-1193}

48. Lane M, Gardner DK. Differential regulation of mouse embryo development and viability by amino acids. J. Reprod. Fertil. 1997;109(1):153-164.

49.Van Kooij RJ, de Boer P, De Vreeden-Elbertse JM, Ganga NA, Singh $\mathrm{N}, \mathrm{TeVelde}$ ER. The neutral comet assay detects double strand DNA damage in selected and unselected human spermatozoa of normospermic donors. Int. J. Androl. 2004; 27(3):140-146.

50. Madeja Z, Waroczyk M, Strabel T, Lechniak D. Use of the hypo-osmotic swelling test for evaluating bull and boar semen quality. Med. Weter. 2003;59(12):1115-1118.

51. Samardžija M, Dobranić T, Krušlin S, Cergolj M, Karadjole M, Prvanović $\mathrm{N}$, et al. The use of the hypoosmotic swelling test and supravital staining in evaluation of sperm quality in boars. Vet arhiv. 2008; 78:279-287.

52. Gadea J, Matas C, Lucas X. Prediction of porcine semen fertility by homologous in vitro penetration (hIVP) assay. Anim. Reprod. Sci. 1998;56(2):95-108.

53. Lechniak D, Kedzierski A, Stanislawski D. The use of HOS test to evaluate membrane functionality of boar sperm capacitated in vitro. Reprod. Dom. Anim. 2002;37(6):379-380.

54. Neild D, Chaves G, Flores M, Mora N, Beconi M, Aguero A. Hypoosmotic test in equine spermatozoa. Theriogenology. 1999;51(4):721-727.

55. Dobranić T, Samardžija M, Cergolj M, Prvanović N. Determination of membrane integrity on canine spermatozoa. Vet. arhiv. 2005;75:2330.

56. Tamuli MK, Watson PF. Effect of temperature of incubation on the development of resistance to cold stress and hypoosmotic stress in boar spermatozoa incubated for up to 24 hours. Proceedings of the $12^{\text {th }}$ Int. Cong. Anim. Reprod. 1992; p.1484-1486.

57. Agarwal A, Sekhon LH. The role of antioxidant therapy in the treatment of male infertility. Hum Fertil (Camb) 2010;13:217-225. doi: 10.3109/14647273.2010.532279.

58. Natali I. Sperm Preparation Techniques for Artificial Insemination - Comparison of Sperm Washing,Swim Up, and Density Gradient Centrifugation Methods. In: Dr. MiladManafi, editor. Artificial Insemination in Farm Animals, 2011. ISBN: 978-953-307-3125, InTech, Available from: http://www.intechopen.com/books/ artificial-insemination-in-farm-animals/sperm-preparationtechniques-for-artificial-insemination-comparison-of-spermwashing-swim-up-and-den. 